\title{
Uso de novos materiais para o capeamento pulpar (hidroxiapatita - HAp e fosfato tricálcico - $\beta$-TCP)
}

\section{(The use of new materials for pulp capping (hydroxyapatite - HAp and tricalcium phosphate - $\beta$-TCP))}

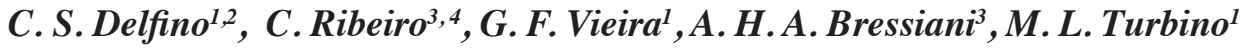 \\ ${ }^{1}$ Departamento de Dentística da Faculdade de Odontologia da Universidade de S. Paulo, Av. Prof. Lineu Prestes \\ 2227, Cidade Universitária, S. Paulo, SP 05508-900 \\ ${ }^{2}$ Clínica Odontológica Integrada da Faculdade de Odontologia da Universidade Cruzeiro do Sul, Av. Dr. Ussiel \\ Cirilo 225, S. Miguel, S. Paulo, SP 08060-070 \\ ${ }^{3}$ Centro de Ciência e Tecnologia de Materiais - CCTM, Instituto de Pesquisas Energéticas e Nucleares - IPEN/ \\ CNEN-SP, Av. Prof. Lineu Prestes 2242, Cidade Universitária, S. Paulo, SP 05508-000 \\ ${ }^{4}$ Centro de Engenharia, Modelagem e Ciências Sociais Aplicadas - CECS, Universidade Federal do ABC, Rua \\ Santa Adélia 166, Bangu, Santo André, SP 09210-170
}

\begin{abstract}
Resumo
O capeamento pulpar é uma medida importante e muito usada no cotidiano da prática odontológica e, quando realizado de forma consciente, baseado em um bom diagnóstico da condição pulpar no momento da exposição, pode prevenir o dente de sofrer uma intervenção endodôntica. Além do hidróxido de cálcio, outros materiais vêm sendo testados quanto a sua ação em promover o reparo pulpar pela formação de ponte de dentina, após capeamento pulpar direto. Uma das alternativas de materiais viáveis para o capeamento pulpar são as cerâmicas à base de fosfatos de cálcio, destacando-se a hidroxiapatita (HAp) e o fosfato tricálcico $(\beta-\mathrm{TCP})$. Estes materiais não promovem a formação de área necrótica, característica da utilização do hidróxido de cálcio, são biocompatíveis e favorecem o reparo do tecido pulpar. Para avaliar os efeitos desses materiais no capeamento pulpar foi realizada esta revisão de literatura, abordando desde a resposta do tecido pulpar, até o protocolo para o uso clínico.
\end{abstract}

Palavras chave: hidroxiapatita; hidróxido de cálcio, proteção pulpar direta.

\begin{abstract}
Pulp capping is an important measure and one with a high rate of use in daily dental practice, and when it is conscientiously performed, based on good diagnosis of the pulp condition at the time of its exposure, it may prevent the tooth from requiring endodontic intervention. In addition to calcium hydroxide, other materials have been tested with regard to their action in promoting pulp repair by the formation of a dentin bridge after direct pulp capping. Some of the feasible alternative materials for pulp capping are calcium phosphate-based ceramics, with hydroxyapatite (HAp) and tricalcium phosphate ( $\beta$-TCP) being outstanding. These materials do not promote formation of a necrotic area, characteristic of the use of calcium hydroxide, are biocompatible and favor pulp tissue repair. To evaluate the effects of these materials on pulp capping, this literature review was conducted, the approach being wide ranging in scope, from pulp response through to the protocol for clinical use.
\end{abstract}

Keywords: hydroxyapatite, calcium hydroxide, direct pulp protection.

\section{INTRODUÇÃO}

A cárie dentária e o dano traumático representam as maiores ameaças para os dentes. Mediante a exposição pulpar, um procedimento de capeamento pulpar ou pulpotomia busca preservar a vitalidade da polpa, permitindo o desenvolvimento radicular normal. Historicamente, o hidróxido de cálcio foi o material de escolha para estes procedimentos e apicificação $[1,2]$. Recentemente, têm sido propostos materiais alternativos que agreguem os efeitos positivos do hidróxido de cálcio, visando uma melhor biocompatibilidade de forma a estimular respostas reacionais do tecido, para que haja formação de uma barreira de dentina, selando a área exposta e protegendo a polpa [3]. O processo de capeamento pulpar depende primariamente da capacidade do tecido pulpar em se regenerar. A polpa é um tecido conjuntivo altamente especializado, responsável pela vitalidade do dente. Sua principal função é produzir dentina, mas também exerce as funções de nutrição, proteção e reparação. 
Vários fatores interferem nessa reparação, como, idade do dente, condição periodontal e estágio de formação da raiz. Fatores clínicos como tamanho da exposição pulpar, natureza da exposição (traumática, mecânica ou lesão de cárie) e contaminação microbiológica do local, também são fatores determinantes para o sucesso do capeamento pulpar [4]. Contudo, a atuação desses fatores clínicos na reparação tecidual, ainda não está totalmente esclarecida. O objetivo do capeamento pulpar é facilitar a cura da polpa pelo estímulo do tecido pelo material capeador, produzindo tecido mineralizado e fechando a área de exposição. Esta ação controla a microinfiltração e a penetração de bactérias e contaminantes. Alguns estudos sugerem que o material capeador apresente característica de reabsorção, caso do $\mathrm{Ca}(\mathrm{OH})_{2}$ e de fosfatos de cálcio de razão molar $\mathrm{Ca} / \mathrm{P}$ inferior a 1,5 , e não afete a vitalidade do tecido pulpar $[5,6]$. Uma variedade de materiais vem sendo utilizada para capeamento pulpar, mas o hidróxido de cálcio, que apresenta efeito bactericida, permanece ainda como padrão $[4,7,8]$. Porém, após o capeamento pulpar com esse agente convencional alcalino, em decorrência do elevado pH local, o tecido pulpar adjacente geralmente é alterado, formando uma zona de obliteração $(0,2-0,5 \mathrm{~mm})$ [9]. No tecido subjacente, mais apical, ocorre a formação de uma zona de coagulação e necrose [10-12]. Em outros casos, ocorre a formação de uma dentina reparadora sob o hidróxido de cálcio e de uma ponte de dentina mineralizada, fechando a exposição pulpar [4]. A avaliação do potencial reparador de um material em situações de agressão à polpa é essencial para a aplicação consciente de um material na prática clínica. Dessa forma, o mercado endodôntico, impulsionado por profissionais que anseiam por materiais de fácil manuseio e que alcancem bons resultados, estimula o aparecimento de outros materiais que substituam o hidróxido de cálcio. Alguns fatores podem comprometer a utilização do hidróxido de cálcio, como seu comportamento acelerado de degradação, sendo muitas vezes incompatível com o tempo de reparação, defeitos em forma de túnel na ponte de dentina formada, efeito cáustico intenso e propriedade de selamento inadequada, permitindo a microinfiltração de contaminantes [13]. Isto torna a busca por novos materiais para proteção pulpar indispensável. Dessa forma, considerando o constante desenvolvimento de novos materiais odontológicos e o aprimoramento das técnicas para avaliação de suas propriedades, faz-se necessário consolidar alguns conceitos, avaliar desempenhos clínicos, assim como estudar possíveis alternativas para melhorá-los. Assim, a utilização de materiais cerâmicos particulados, como: hidroxiapatita (HAp) e $\beta$-fosfato tricálcico ( $\beta$-TCP), que são indutores de mineralização e, já empregados efetivamente em outras aplicações odontológicas pode ser uma alternativa segura também para o capeamento pulpar $[10,12]$.

Com base nessas observações, o objetivo deste estudo foi o de realizar uma revisão da literatura sobre os processos que envolvem o capeamento pulpar, considerando a utilização de materiais cerâmicos nesse procedimento.

\section{Revisão}

\section{Dentes: macro e microestrutura composicional}

A estrutura dentária é composta de diferentes regiões, Fig. 1 [14]. A camada mais externa dos dentes atua como um revestimento, e é chamada esmalte. Este revestimento é altamente mineralizado e acelular, não permitindo, portanto, que seja considerado como um tecido vivo. No seu estágio de maturação pode apresentar uma quantidade superior a 97\% de fase inorgânica, predominantemente HAp [15].

A fase da hidroxiapatita do esmalte, em particular, apresenta alta cristalinidade, sendo maior que a da dentina e do próprio osso, como é verificado nos gráficos de difração de raios X, Fig.2, comprovada pela definição e estreitamento dos picos referente a esta fase. Apesar da existência de substituições em sua estrutura, é a fase que mais se aproxima da HAp estequiométrica de todos os tecidos mineralizados dos vertebrados [16].

A região do esmalte é caracterizada pela presença de porosidade suficiente apenas para difusão e reações que ocorrem no interior de sua estrutura, como dissolução ácida (cáries) e remineralização pela ação salivar [17].

A dentina, outra porção mineral do dente, representa a interface entre polpa e esmalte, na superfície coronária e, com o cemento (fina camada que envolve a porção radicular do dente), na superfície radicular [14]. A dentina é um tecido conjuntivo calcificado que possui milhares de canalículos por milímetro quadrado. A estimativa da densidade canalicular varia de 40 a 70 mil canalículos por milímetro quadrado, dependendo da distância que se encontra em relação à polpa; quanto maior a proximidade com a polpa, maior a concentração destes canalículos [14, 18]. A dentina, Fig. 3, entre os canalículos é chamada de dentina intercanalicular, fase rica em matriz orgânica, porém menos calcificada que a dentina peritubular na periferia dos canalículos [14].

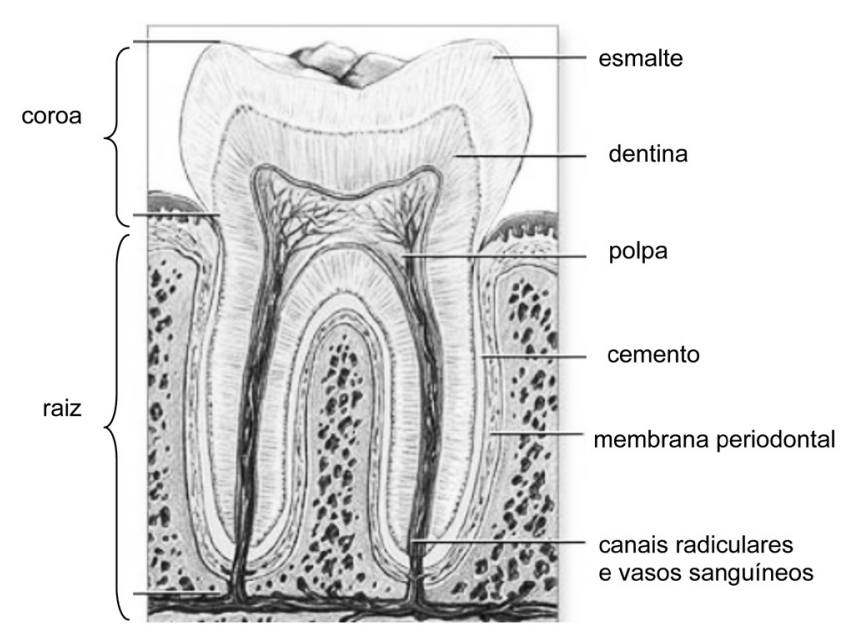

Figura 1: Esquema simplificado da estrutura de um dente [14]. [Figure 1: Schematic drawing of a tooth [14].] 


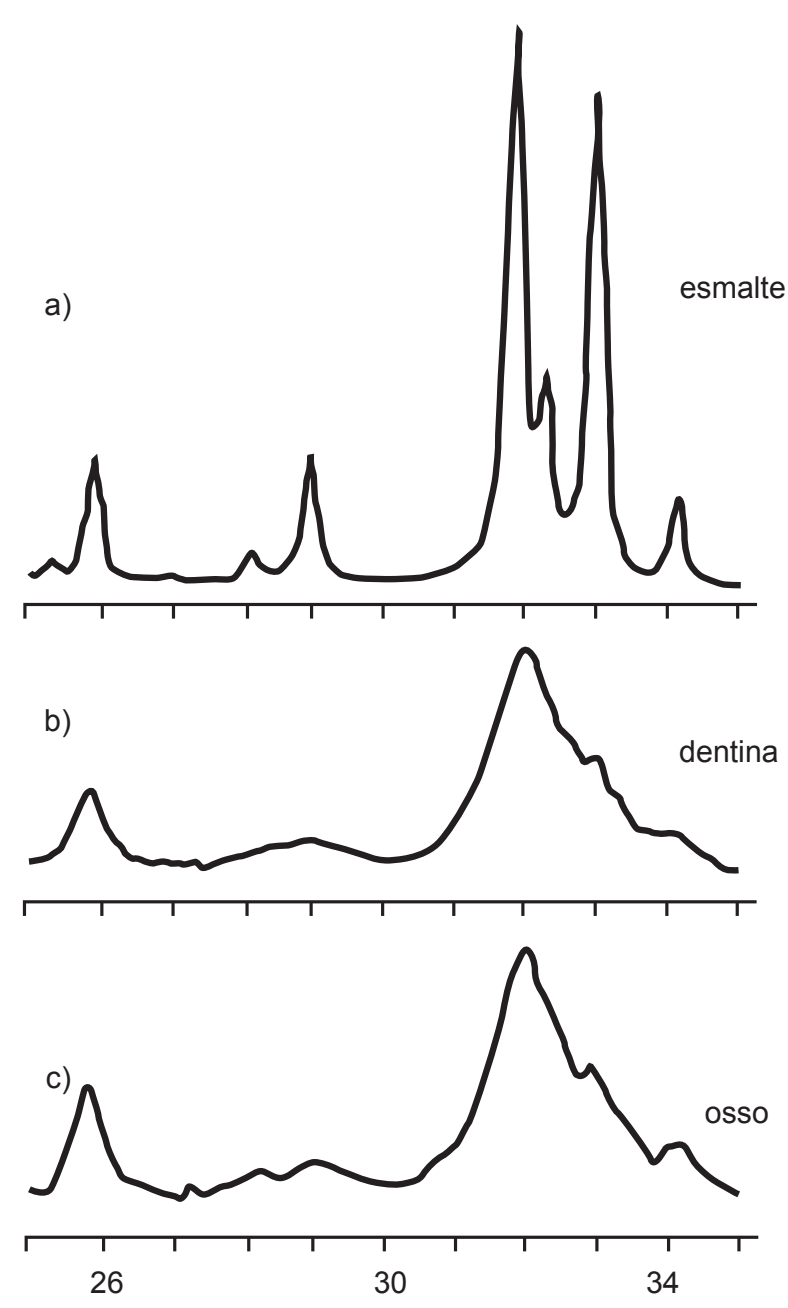

Figura 2: Difratogramas de raios $\mathrm{X}$ das fases minerais presentes no esmalte (A), na dentina (B) e no osso (C) [16].

[Figure 2: X-ray diffraction patterns of the mineral phases in enamel (A), dentin $(B)$ and bone $(C)$ [16].]

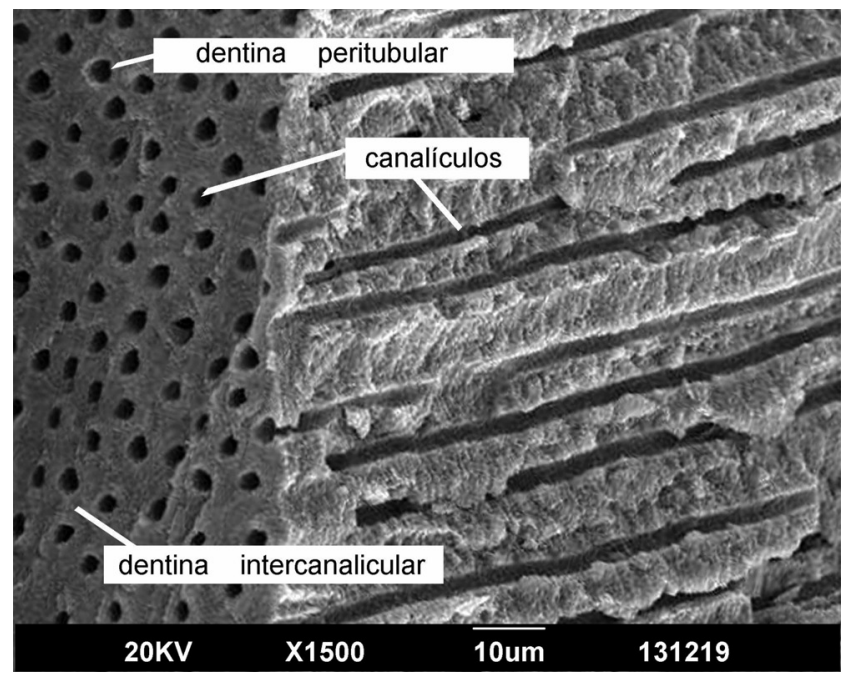

Figura 3: Micrografia (MEV) típica da dentina peritubular e dentina intercanalicular.

[Figure 3: Typical micrograph (SEM) of peritubular dentin and intercanalicular dentin.]

Tanto a dentina quanto o cemento são tecidos conectivos mineralizados, contendo uma matriz orgânica de colágeno e proteínas, e parte inorgânica, basicamente apatita biológica.É importante ressaltar que, comparativamente ao tecido ósseo, a dentina e o cemento apresentam pouca vascularização [14]. Já a porção mais interna da cavidade dentária é chamada de polpa. A polpa dental é constituída por tecido conjuntivo frouxo que ocupa a cavidade interna do dente, sendo composta por células, vasos, nervos, fibras e substâncias intercelulares. Anatomicamente a polpa está dividida em polpa coronária e polpa radicular, correspondendo respectivamente, à coroa e à raiz anatômicas [14]. Similarmente aos ossos, a parte inorgânica dos dentes também é composta por fosfatos de cálcio. A Tabela I apresenta a composição elementar das

Tabela I - Composição comparativa dos tecidos calcificados em humanos com maturação completa [19, 20]. [Table I - Comparative composition of completely mature human calcified tissues [19, 20].]

\begin{tabular}{|c|c|c|c|c|c|}
\hline $\begin{array}{c}\text { Composição } \\
\text { (\% massa) }\end{array}$ & esmalte & dentina & cemento & Osso & HAp \\
\hline $\mathrm{Ca}^{+2}$ & 36,5 & 35,1 & & 34,8 & 39,6 \\
\hline $\mathrm{P}^{-5}$ & 17,7 & 16,9 & & 15,2 & 18,5 \\
\hline Ca/P (razão molar) & 1,63 & 1,61 & & 1,71 & 1,67 \\
\hline $\mathrm{Na}^{+}$ & 0,5 & 0,6 & & 0,9 & - \\
\hline $\mathrm{Mg}^{+2}$ & 0,44 & 1,23 & & 0,72 & - \\
\hline $\mathrm{K}^{+}$ & 0,08 & 0,05 & & 0,03 & - \\
\hline $\mathrm{CO}_{3}^{-2}$ & 3,5 & 5,6 & & 7,4 & - \\
\hline $\mathrm{F}^{-}$ & 0,01 & 0,06 & & 0,03 & \\
\hline $\mathrm{C}^{--}$ & 0,3 & 0,01 & & 0,13 & - \\
\hline $\mathrm{P}_{2} \mathrm{O}_{7}^{-4}$ & 0,022 & 0,10 & & 0,07 & \\
\hline material orgânico & 1,5 & 20 & 25 & 25 & - \\
\hline material inorgânico & 97 & 70 & 60 & 65 & 100 \\
\hline Água & 1,5 & 10 & 15 & 10 & - \\
\hline
\end{tabular}


diferentes regiões de uma estrutura dental, comparada ao osso e a fase hidroxiapatita, que é predominante nos tecidos mineralizados. [19, 20]

\section{Fosfatos de cálcio na Odontologia}

Cerca de 60 anos depois que Albee [21] relatou a osteogênese em defeitos ósseos tratados com o uso de um fosfato de cálcio trifásico, uma série de pesquisadores sugeriram o uso das cerâmicas à base de fosfatos de cálcio como materiais para implante odontológico [16, 22]. Estas cerâmicas, em específico, devem ser biocompatíveis e osteocondutoras, podendo ser classificadas em: reabsorvíveis ou bioativas (superfície ativa). O fosfato tricálcico (TCP), $\mathrm{Ca}_{3}\left(\mathrm{PO}_{4}\right)_{2}$ apresenta natureza reabsorvível, fazendo com que parte do material seja dissolvido, fornecendo matériaprima para o crescimento e manutenção do novo tecido, o que facilita o processo de osteocondução [23]. Já a hidroxiapatita (HAp), $\mathrm{Ca}_{10}\left(\mathrm{PO}_{4}\right)_{6}(\mathrm{OH})_{2}$, é um material de superfície ativa que promove uma adequada fixação pela habilidade de desenvolver ligações em sua interface com o osso, permanecendo no local para dar sustentação ao novo tecido. Tais características permitem a estas cerâmicas uma gama de aplicações que se estende desde a utilização como substitutos funcionais para o reparo e preenchimento de cavidades ósseas ou recobrimento de implantes metálicos, até o uso como veículos para liberação controlada de fármacos e scaffolds para engenharia de tecidos. Porém, os fosfatos de cálcio não são recomendados em aplicações que exigem grande sustentação de cargas [23, 24]. As aplicações na área odontológica destes materiais envolvem: colocação do enxerto imediatamente após extração do elemento dental para evitar, ou minimizar, a reabsorção do rebordo alveolar; preenchimento ósseo em defeitos periodontais, prevenindo a reabsorção óssea e perda do dente; aumento da dimensão vertical para melhor ajuste da prótese; recobrimento de implantes metálicos, melhorando a adesão osso-implante e estabilidade; correção de assimetrias mandibulares e/ou defeito maxilo-faciais e fissuras palatinas [14, 16, 20]. Estes materiais também podem ter sua aplicação na endodontia sendo utilizados como capeadores pulpares, como será enfatizado nesta revisão.

A HAp já vem sendo utilizada dentro de focos estratégicos na área médica com altas taxas de sucesso, verificada em estudos in vivo pela habilidade de desenvolver ligações químicas com a apatita óssea, promovendo a osteointegração [25]. É utilizada, também, em implantes de ouvido médio, formando um selo contra bactérias, e em uma série de dispositivos ortopédicos [24]. Já o TCP é capaz de se adaptar facilmente aos tecidos duros e gradualmente converter-se em hidroxiapatita, maior componente dos tecidos duros do corpo. Esta conversão ocorre de acordo com a estequiometria da fase cerâmica em condição adequada de $\mathrm{pH}$ [19]. Transformações de fases em implantes de fosfatos de cálcio "in situ" devem-se principalmente ao processo de hidrólise e difusão de espécies alcalinas, que são facilmente substituídas por íons seletivos presentes nos fluidos corpóreos.
É importante acrescentar que somente as fases HAp e DCPD (dicálcio fosfato dihidratado) são estáveis em condições de $\mathrm{pH}$, pressão de oxigênio e temperatura biológicas, sendo o TCP, uma fase transiente do ciclo de biomineralização $[26,27]$. No entanto, isto não significa que outras fases não possam ser observadas em diferentes estágios de maturação dos tecidos mineralizados. O TCP pode apresentar duas formas polimórficas: monoclínica $(\alpha-\mathrm{TCP})$ e romboédrica $(\beta-\mathrm{TCP})$, sendo esta mais estável. Ele possui um papel importante no processo de biomineralização óssea, sendo um dos precursores da apatita biológica em meio fisiológico $[28,29]$. Esse material não causa danos ao organismo humano, comprovando sua biocompatibilidade pela ausência de características, como, sinais de degeneração do tecido, infecção ou uma não-hemocompatibilidade [10, 30-32]. Cristalograficamente a HAp é mais similar aos tecidos duros do que o $\beta$-TCP, sua razão de reabsorção é extremamente baixa comparada ao $\beta$-fosfato tricálcico, por isso a fase hidroxiapatita não pode ser considerada reabsorvível. Um implante de HAp permanecerá mesmo depois de 3 ou 4 anos de colocação, o TCP, por outro lado, sendo reabsorvível, desaparecerá parcialmente, em períodos de 6 a 15 semanas, dependendo da estequiometria e cristalinidade $[24,33]$. Como um dos principais questionamentos sobre a viabilidade de um material para fins odontológicos é o tempo e qualidade da resposta do organismo do hospedeiro à sua presença, a cerâmica bifásica $(\mathrm{BCP})$, contendo as fases HAp e TCP, pode se tornar muito atrativa pela rápida capacidade de resposta às complexas reações do processo de dentinogênese, sem qualquer dano [34]. Esta resposta particular deve-se, em parte, ao efeito sinérgico das duas cerâmicas atuando simultaneamente, já que apresentam evolução e adaptação similares para os tecidos [35]. Ademais, estas cerâmicas podem acelerar a deposição de uma camada superficial de apatita na presença de fluidos pulpares, estimulando a formação de dentina, ajudar na manutenção da integridade do tecido pulpar e induzir a formação de uma neodentina adjacente à polpa de maneira mais rápida de quando são utilizadas na forma monofásica [32]. Tal comportamento está associado à propriedade da bioatividade destes materiais. Um material bioativo está propenso, em fluidos corpóreos, à nucleação e crescimento de cristais de apatita carbonatada (apatita biológica), análogos ao mineral ósseo, e também a fazer associações específicas com proteínas ósseas, sendo o ponto inicial para reconstrução [36]. A formação de apatita carbonatada (espécie de fosfato de cálcio contendo a espécie $\mathrm{CO}_{3}{ }^{-2} \mathrm{em}$ sítios hidroxila, tipo A ou sítios fosfato, tipo B) envolve as etapas de acidificação do meio, como conseqüência da interação celular com o material, dissolução e formação de apatita associada a uma matriz orgânica. Durante a dissolução, além dos íons mais comuns: $\mathrm{Ca}^{+2}, \mathrm{PO}_{4}^{-3}, \mathrm{OH}^{-}, \mathrm{H}^{+}, \mathrm{HPO}_{4}^{-2}$, $\mathrm{H}_{2} \mathrm{PO}_{4}^{-}$, íons complexos, como, $\mathrm{CaH}_{2} \mathrm{PO}_{4}^{+} \mathrm{e} \mathrm{CaOH}^{+}$, podem ser encontrados na camada hidratada que é formada ao redor do material. Esta camada contribui para o desenvolvimento de cargas superficiais, que influenciam na atividade celular e definem o tipo de interface formada. A matriz orgânica 
associada à apatita pode incorporar diferentes íons, como o carbonato ou magnésio do fluido biológico, necessários à produção de uma matriz extracelular, e conseqüentemente promover a mineralização simultânea de fibrilas de colágeno e incorporação de cristais de hidroxicarbonatoapatita recém formados no remodelamento do novo tecido duro [25, 36]. A incorporação de outros íons na estrutura pode afetar diretamente a cristalinidade e a solubilidade do fosfato de cálcio original. Quando um agente bioativo, como a HAp, é aplicado sobre o tecido pulpar exposto há uma diferenciação de células pulpares em células produtoras de tecido calcificado, de um modo diferente de quando o $\mathrm{Ca}(\mathrm{OH})_{2}$ é utilizado. A HAp atua modificando o meio ambiente das células, rompendo seu equilíbrio, pela alteração das concentrações iônicas dos íons cálcio e hidroxila presentes em sua estrutura, estes se difundem, modificando as interações dinâmicas entre as células e sua matriz extra-celular. Estas alterações adaptativas são dependentes do tempo e, algumas células na região podem iniciar a mineralização dentro da matriz, formando um tecido duro semelhante ao osso, conhecido como osteodentina. Com o prosseguimento da atividade sintética dentro das células, elas se tornam mais colunares, polarizadas e agrupadas, adquirindo o fenótipo odontoblástico; desta forma, se adaptam ao novo meio ambiente. Este processo leva à formação de uma barreira ou ponte de dentina no local da exposição [38, 39].

\section{Capeamento pulpar}

A remoção completa do tecido cariado foi, por muito tempo, considerada a estratégia ideal no tratamento de lesões de cárie dentinária [40], independente de sua extensão. Entretanto, especialmente em cavidades profundas, a remoção total da lesão pode resultar em exposição do tecido pulpar, o que requer tratamentos mais invasivos e manipulação direta deste tecido [41]. Outros procedimentos clínicos, como, capeamento pulpar indireto e tratamento restaurador atraumático, baseiam-se no mecanismo de defesa do complexo dentino-pulpar para alcançarem níveis de sucesso adequados $[42,43]$. O processo de conservação da polpa exposta pela aplicação de um capeamento vem sendo estudado desde 1756, quando foi iniciado o seu emprego usando cápsulas de ouro para recobrir a parede do tecido pulpar exposto [44].

A utilização de estruturas teciduais dentárias de animais semelhantes à de humanos, para avaliação da compatibilidade biológica de materiais utilizados em odontologia, tem sido realizada desde a antiguidade, salientando-se o interesse constante na determinação do potencial irritativo das diversas substâncias. O grau de agressividade tecidual dos materiais vem sendo analisado de forma comparativa, em primeira instância, em cultura de células, em tecido conjuntivo subcutâneo e em tecido ósseo de ratos, sendo depois direcionada à avaliação em dentes de animais, como: coelhos, cães e macacos, utilizados por possuírem complexo dentina-polpa muito próximo a dos humanos, quanto à forma e fisiologia diferenciada [45]. O complexo dentina- polpa possui os mesmos mecanismos de reparo do tecido conjuntivo de suporte, modificado por uma série de fatores locais [46].

Após a aplicação direta de um material sobre a polpa exposta espera-se que ocorra a formação de uma ponte de dentina mineralizada, e a manutenção da vitalidade pulpar [47]. Essa ponte de dentina mineralizada, também chamada de ponte dentinária, é definida como uma matriz de dentina formada e depositada por uma nova geração de células, tipo odontoblastos, em resposta a um estímulo forte, depois da morte dos odontoblastos originais (primários), responsáveis pela formação da dentina primária e fisiológica [48]. A reação inflamatória, a permissividade, e o estímulo à formação da ponte de dentina mineralizada, bem como a evolução à estrutura de padrão dentinário, permitem avaliar o grau de irritabilidade e o potencial reparador determinado pelo material odontológico. Embora o hidróxido de cálcio seja o material mais utilizado para o capeamento pulpar $[4,7,8]$ a deposição de tecido duro não parece ser uma propriedade exclusiva desse material [49]. Apesar do fenômeno de calcificação da polpa ser atribuído ao $\mathrm{Ca}(\mathrm{OH})_{2}$, este material não apresenta capacidade de penetração em profundidade na matriz extracelular. Foi relatado que a reparação pulpar pode ser uma resposta natural do tecido pulpar quando exposto a uma irritação de baixa intensidade [50]. O processo de reparo da polpa dentária segue uma série de eventos biológicos ordenados e previsíveis, diferindo pouco de outros tecidos e, geralmente, não depende do tipo de injúria, sendo semelhante ao que ocorre na pele após uma incisão cirúrgica [46]. Fazendo uma comparação mais detalhada, observa-se que durante o preparo de uma cavidade em um dente, ocorre a remoção, tanto de esmalte, como de dentina. $\mathrm{O}$ esmalte representaria o epitélio e o complexo dentinapolpa seria o conjuntivo por ele recoberto; dessa forma não surpreende que a resposta ao reparo dos tecidos dentários seja semelhante à da pele [46]. Porém, quando parte do esmalte é removido, estímulos chegam à polpa e promovem a formação de nova porção de dentina reacional, considerada dentina terciária, ou reparadora. Este mesmo mecanismo de reação é observado quando o preparo cavitário atinge a dentina em diferentes profundidades, sem provocar maiores danos aos odontoblastos e seus prolongamentos. A partir do momento em que a injúria envolve os odontoblastos, a resposta pulpar obedece a uma condição estereotipada, como acontece, por exemplo, na derme. Uma resposta inflamatória envolvendo neutrófilos e macrófagos, seguida de fenômenos proliferativos e secretores, pode ser observada. Novos fibroblastos diferenciam-se a partir de fibroblastos pulpares íntegros e de células perivasculares indiferenciadas, passando a produzir imediatamente uma matriz de colágeno [45]. A formação de uma matriz dentinária e sua posterior mineralização estão na dependência de células secretoras especializadas, os odontoblastos, que, segundo diferentes pesquisadores $[45,46,50]$, teriam origem a partir de células mesenquimais indiferenciadas. O estímulo para esta evolução viria com a formação de uma barreira mineralizada, condição que pode ser satisfeita com o uso de materiais 
especiais, como as biocerâmicas.

Várias cerâmicas de fosfatos de cálcio têm sido testadas como agentes de capeamento. Entre elas destacam-se o $\beta$-fosfato tricálcico ( $\beta$-TCP) e a hidroxiapatita (HAp). Os resultados já relatados sugerem que a HAp e o TCP não prejudicam a polpa dental, sendo efetivas clínicopatologicamente na proteção da polpa dental humana exposta e podendo ser usadas com sucesso como material básico na terapia endodôntica $[10,34]$. Estas cerâmicas podem ser utilizadas na forma particulada, e ao serem misturadas com solução salina ou soluções levemente ácidas, podem ser convertidas em fosfato octacálcico ou hidroxiapatita carbonatada [38]. A utilização destas cerâmicas baseia-se no fato de que a dentina é o melhor protetor da polpa, e que a utilização de materiais capeadores, cujos elementos são os mesmos constituintes da dentina possam resultar em benefício pulpar [51].

A formação de tecido calcificado, induzido por cerâmicas de fosfatos de cálcio, pode agir como substrato indutivo para que outras células tornem-se mais diferenciadas [39]. Uma vez que estas células mesenquimais tenham se diferenciado, parecem preservar a capacidade de formação de tecido mineralizado.

Considerando que a seleção dos materiais para restaurar a estrutura dental deve ser baseada, principalmente, na biocompatibilidade dos mesmos, parece viável utilizar tais materiais cerâmicos para capeamento do tecido pulpar. As cerâmicas de HAp e $\beta$-TCP, são totalmente aceitas pelo organismo [34, 52, 53] e além de não promoverem áreas de necrose, também mostram habilidade em neutralizar o ataque de ácidos inorgânicos [12]. Quando a HAp e o $\beta$-TCP foram comparados, nenhuma diferença significativa ou característica vantajosa foi observada na atuação como agentes de capeamento pulpar [30]. Na comparação entre o hidróxido de cálcio e as cerâmicas de HAp ou TCP, foi observado que a aplicação destes fosfatos de cálcio sobre o tecido pulpar promovem a formação de um novo tecido duro, diferente do promovido pelo hidróxido de cálcio [10]. Apesar do hidróxido de cálcio estimular a formação de um novo tecido, há evidência de área necrótica, em sítios imediatamente abaixo do local de sua aplicação. Diferentemente da resposta quando cerâmicas à base de fosfatos de cálcio são aplicadas, não havendo neste caso, qualquer aposição de outro tecido adjacente ao implante e ausência de necrose, além disso, são estabelecidas fortes ligações interfaciais que conferem propriedades adequadas para regeneração do novo tecido. Em relação ao hidróxido de cálcio, quanto à adesão de moléculas como a fibronectina, sugere-se que a dentinogênese reparativa observada sobre o capeamento com este material seja causada pela produção de cristais de calcita a partir de reações com o plasma ou fluidos pulpares, que permitem a adesão da fibronectina, moléculas que são um gatilho de ligação para diferenciação celular. Sabe-se que a HAp na presença de plasma induz a formação de cristais de apatita carbonatada que apresentam grande afinidade com a fibronectina, prevendo, portanto um processo de dentinogênese muito similar ao $\mathrm{Ca}(\mathrm{OH})_{2}[54]$.

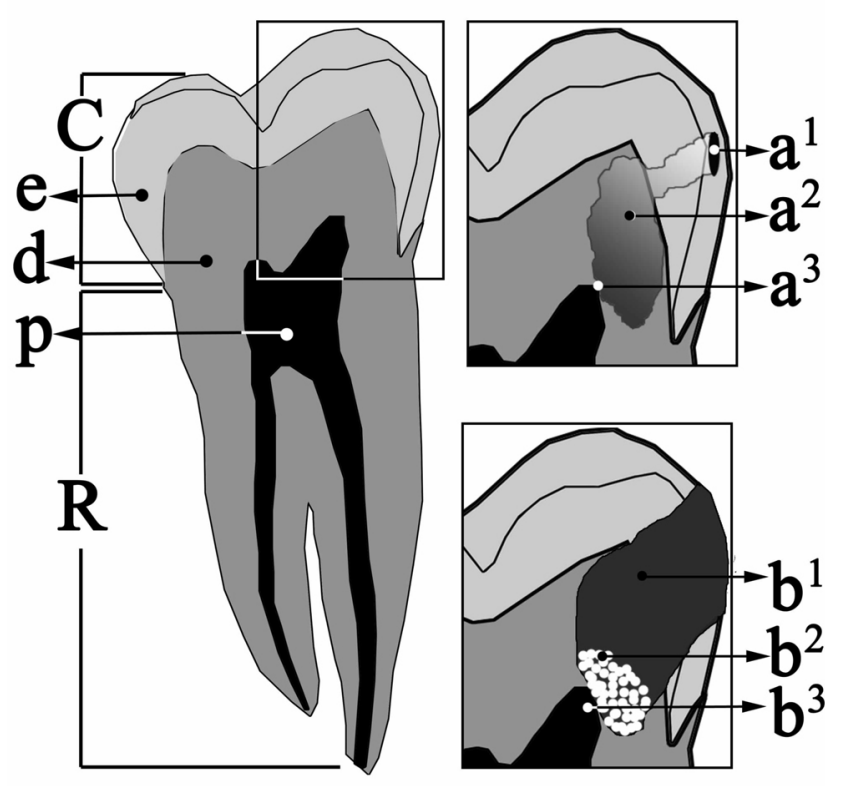

Figura 4: Técnica de capeamento pulpar. C: coroa dental, parte do dente recoberta pelo esmalte; R: raiz; e: esmalte dental, tecido altamente mineralizado; d: dentina, tecido formado por pouca quantidade de minerais possuindo túbulos com prolongamento de células; p: polpa dental, altamente vascular e com células específicas; a1: lesão de cárie em esmalte; a2: lesão de cárie em dentina; a3: porção da lesão cárie que atingiu a polpa; b1: preparo cavitário após limpeza do tecido cariado e preenchido por material de proteção; b2: material cerâmico em contato direto com a polpa; b3: região da polpa em contato com o material cerâmico aonde será formada a ponte de dentina.

[Figure 4: Pulp capping technique. C: dental crown, part of tooth covered by enamel; R: root; : dental enamel, highly mineralized tissue; $d$ : dentin, tissue formed by a small quantity of minerals, having tubules with elongated cells; p: dental pulp, highly vascular and has specific cells; a1: caries lesion in enamel; a2: caries lesion in dentin; a3: portion of caries lesion that has attained the pulp; b1: cavity preparation after cleaning away carious tissue and filled with protective material; b2: ceramic material in direct contact with the pulp; b3: region of the pulp in contact with the ceramic material, where the dentin bridge will be formed.]

A aplicação de componentes que fazem parte da constituição da matriz dentinária, como a HAp, sobre o tecido pulpar, estimula a diferenciação celular e a síntese de matriz extracelular por odontoblastos. Desta forma, a matriz dentinária deve funcionar como um reservatório de espécies bioativas, que podem influenciar o comportamento das células pulpares. A presença destes componentes dentro da matriz dentinária pode contribuir para a manutenção do fenótipo odontoblástico, na medida em que ele permanece em contato com a matriz [55]. O protocolo para o uso clínico desses materiais é o mesmo adotado para o hidróxido de cálcio na forma particulada. A área de exposição pulpar deve ser irrigada com água destilada ou solução salina, e 
seca com algodão estéril até ocorrência da hemostasia. O material cerâmico particulado (HAp ou TCP) deve ser aplicado na área exposta e, em seguida, essa região pode ser coberta com os materiais usuais, como as resinas sintéticas, guta percha (substância extraída a partir do látex, seguida de processo de coagulação e purificação, facilmente moldável e com propriedade adesiva), cimento de hidróxido de cálcio ou cimento de ionômero de vidro - nome comercial de um cimento híbrido à base de silicato e policarbonato de zinco, e a outra porção da cavidade pode ser preenchida com cimento provisório ou também com o cimento de ionômero de vidro $[10,12,56]$. A Fig. 4 apresenta um esquema típico de capeamento pulpar.

Esses materiais cerâmicos são facilmente encontrados no mercado, porém o custo ainda é relativamente alto quando comparado ao custo do hidróxido de cálcio. Atualmente estima-se um custo cerca de seis vezes maior. Mas como ainda não são amplamente utilizados na clínica odontológica acredita-se que futuramente esse custo diminua, ao serem solicitados com maior freqüência em função de suas propriedades mais adequadas. É importante destacar os benefícios que esses materiais fornecem, quanto à ausência de áreas de necrose [12] e habilidade de desenvolver ligações efetivas na interface material/tecido pulpar [26, 27].

\section{CONCLUSÃO}

Pode-se sugerir que as cerâmicas de fosfatos de cálcio, como HAp e $\beta$-TCP, representam uma perspectiva futura de opção mais segura na utilização como agentes para o capeamento pulpar, apresentando efeitos positivos comparativamente ao hidróxido de cálcio. Estas cerâmicas são capazes de manter a viabilidade do tecido e promover uma reparação da exposição, além da alta biocompatibilidade, diferente da ação do cimento de óxido de zinco e outros materiais disponíveis. A formação da camada superficial de apatita, na presença de fluidos pulpares, característica típica de materiais bioativos estimula a formação de dentina. Porém, ainda há necessidade de novos estudos experimentais, assim como, acompanhamento de casos clínicos com sua utilização.

\section{REFERÊNCIAS}

[1] A. Consolaro, "Cárie dentária. Histopatologia e correlações clínico-radiográficas", Ed. Consolaro, S. Paulo, SP (1996) 48.

[2] J. Hebling, E. M. A. Giro, C. A. S. Costa. J. Dent. 27 (1999) 557.

[3] C. A. Falster, F. B. Araujo, L. H. Straffon, J. E. Nor. Pediatr Dent. 24, 3 (2002) 241.

[4] J. H. Camp, E. J. Barrett, F. Pulver, "Pediatric endodontics: endodontic treatment for the primary and young, permanent dentition", in: S. Cohen, R. C. Burns, "Pathways of the Pulp. St Louis: CV Mosby (2002) 797.

[5] B. R. Oguntebi, A. Clark, J. Wilson. J. Dent. Res. 72, 2 (1993) 484.
[6] B. R. Oguntebi, T. Heaven, A. E. Clark, F. E. Pink, J. Endod. 21, 2 (1995) 79.

[7] M. Maroto, E. Barberia, M. Arenas, T. Lucavechi, Dent. Traumatol. 22 (2006) 160.

[8] R. A. Ribeiro, S. I. Myaki, M. A. Gioso, N. S. Araújo, Pesq. Odont. Bras. 14 (2000) 47.

[9] T. Kashiwada, M. Takagi, Bull. Tokyo Med. Dent. Univ. 38, 4 (1991) 45.

[0] M. Furusawa, K. Kakagawa, Y. Asai, Bull. Tokyo Dent. Coll. 32 (1991) 111.

[1] H. R. Stanley, Oral Surg. Oral. Med. Oral. Pathol. 68 (1989) 638.

[2] Y. Yoshimine, K. Maeda, Oral Surg. Oral. Med. Oral Pathol. Oral Radiol. Endod. 79 (1995) 351.

[3] A. H. B. Schuurs, R. J. M. Gruythuysen, P. R. Wesselink, Endod. Dent. Traumatol. 16 (2000) 240.

[4] S. V. Dorozhkin, Materials 2 (2009) 399.

[5] L. C. Bonar, M. Shimizu, J. E. Roberts, R. G. Griffin, M. J. Glimcher, J. Bone Miner. Res. 6 (1991) 1167.

[6] R. Z. Legeros, Adv. Dent. Res. 2 (1988) 164.

[7] P. H. Keyes, Arch. Oral. Biol. 1, 4 (1970) 304.

[8] L. Björndal, T. Larsen, Caries Res. 34 (2000) 502.

[9] R. Z. Legeros, Monographs in Oral 15 (1991).

[20] V. Sergey, Dorozhkin, J. Mater. Sci. 44 (2009) 2343.

[2] F. H. Albee, Ann. Surg. 71 (1920) 32.

[22] K. De Groot, Zahnarztl Mitteil. 75 (1985) 1938.

[23] M. Alcaide, M. C. Serrano, R. Pagani, S. SánchezSalcedo, M. Vallet-Regí, M. T. Portolés, Biomater. 30, 1 (2009) 45 .

[24] L. L. Hench, J. Wilson, Introduction to Bioceramics, World Sci. Publ. Co., New Jersey, EUA (1993).

[25] T. Albrektsson, B. Albrektsson, Osseointegration of bone implants, Acta Orthopedic. Scand. 58 (1987) 567.

[26] Y. Mandai, S. Shimada, F. Sugihara, J. Jpn. Dent. Mater. 6 (1987) 403.

[27] Y. Yoshimine, A. Akamine, M. Mukai, M. Maeda, M. Matsukura, M. Kimura, T. Makishima, Biomater. 14 (1993) 403.

[28] B. D. Ratner, A. S. Hoffman, F. J. Schoen, J . E. Lemons, „Biomaterials Science. An introduction to Materials in Medicine“, Ed. Academic Press (1996) cap. 2.

[29] A. Ravaglioli, A. A. Krajewski, Biomater. 2 (1981) 105. [30] Y. Hayashi, M. Imai, K. Yanagiguchi, I. L. Viloria, T. Ikeda, J. Endod. 25 (1999) 225.

[3] S. O. Rogero, F. J. C. Braga, O. Z. Higa, Mater. Sci. Forum 299 (1999) 44.

[32] L. A. Santos "Desenvolvimento de cimento de fosfato de cálcio reforçado por fibras para uso na área médicoodontológica", Tese Dr., Faculdade de Odontologia, UNICAMP (2002) 95 p.

[33] C. Lavernia, J. M. Schoenung, Am. Ceram. Soc. Bull. 70, 1 (1991) 95.

[34] B. Enkel, C. Dupas, V. Armengol, J. Akpe Adou, J. Bosco, G. Daculsi, A. Jean, O. Laboux, R. Z. LeGeros, P. Weiss, Expert. Rev. Med. Devices 5, 4 (2008) 475.

[35] C. Ribeiro, "Processamento e caracterização de cerâmicas à base de hidroxiapatita e fosfato tricálcio", Diss. 
Mestrado, Instituto de Pesquisas Energéticas e Nucleares, USP, S. Paulo, SP (2003) 89p.

[36] J. E. Lemons, Bone 19 (1996) 121S.

[37] S. V. Dorozhkin, "A review on the dissolution models of calcium apatites", Progr. Crystal Growth Charact. Mater. (2002) 45-61.

[38] K. Yoshiba, N. Yoshiba, M. Iwaku, Endod. Dent. Traumatol. 10, 3 (1994) 113.

[39] T. B. Kardos, A. R. Hunter, S. M. Hanlin, E. E. Kirk, Endod. Dent. Traumatol. 14, 3 (1998) 105.

[40] C. F. Cox, R. K. Sübay, E. Ostro S. Suzuki S. H. Suzuki, Oper. Dent. 21, 1 (1996) 4.

[4] H. I. Iost, J. H. Costa, H. H. Rodriguers, R. A. Roca, Rev. Assoc. Bras. Odont. 3, 1 (1995) 25.

[42] T. Fusayama, Oper. Dent. 4 (1979) 63.

[43] M. Fitzgerald, R. J. Heys, Oper. Dent. 16 (1991) 101.

[44] P. Pfaff, "Abhandlung von den Zähnen des menschlichen

Körpers und deren Frankheiten”, Berlin: 1756, apud: L.

Catanhola, "Conservation de la vitalidad de la pulpa en la operatoria dental", Mundi, Buenos Aires, Argentina (1956).

[45] C. Benatti Neto, "Compatibilidade biológica de materiais odontológicos no complexo dentino-pulpar", Tese Livre Docência, Faculdade de Odontologia da UNESP, Araraquara, S. Paulo, SP (2000) 123 p.
[46] A. R. Ten Cate, "Histologia bucal. Desenvolvimento, estrutura e função", $2^{a}$ Ed. Guanabara-Koogan, Rio de Janeiro, RJ (1988).

[47] C. Turner, F. J. Courts, H. R. Stanley, ASDC J. Dent. Child. 54 (1987) 423.

[48] A. J. Smith, N. Cassidy, H. Perry, C. Begue-Kirr, J. V. Ruch, H. Lesot, Int. J. Dev. Biol. 39 (1995) 273.

[49] C. F. Cox, C. L. Keall, H. J. Keall, E. Ostro, G. Bergenholtz, J. Prosthet. Dent. 57 (1987) 1.

[50] C. T. Hanks, G. Bergenholtz, J. S. Kim. J. Oral Pathol. 12, (1983) 356.

[51] B. R. Oguntebi, T. Heaven, A. E. Clark, F. E. Pink, J. Endod. 21, 2 (1995) 79.

[52] O. Gauthier, E. Goyenvalle, J-M. Bouler, J. Guicheus, P. Pilet, P. Weiss, G. Daculsi, J. Mater. Sci.: Materials in Medicine 12 (2001) 385.

[53] K. A. Lacerda, F. S. Lameiras, V. V. Silva, REM: R. Esc. Minas 59 (2006) 217.

[54] D. Seux, M. L. Couble, D. J. Hartmann, J. P. Gauthier, H. Magloire, Arch. Oral Biol. 36, 2 (1991) 117.

[55] A. J. Sloan, A. J. Smith, Arch. Oral Biol. 44 (1999) 149. [56] A. B. Nascimento, U. F. Fontana, H. M. Teixeira, C. A. Costa, Am. J. Dent. 13, 1 (2000) 28.

(Rec. 13/10/2009, Ac. 29/03/2010) 